УДК 338.2

DOI: $10.21779 / 2500-1930-2020-35-1-19-24$

\title{
О.М. Алиев
}

\section{Анализ проблем сотрудничества власти и бизнеса}

Дагестанский государственный университет, филиал в г. Кизляре; Россия, 368832, г. Кизляр, ул. С. Стальского, 1e; оаот651@таil.ru

Значение бизнеса в развитии экономики России постепенно усиливается. Для повышения отдачи от государственно-частного партнерства требуется открытость и честность в сотрудничестве между бизнесом и властью, соблюдение взаимной целесообразности в достижении целей как общества, так и собственников бизнеса. Рассмотрены проблемные зоны в сегодняшнем диалоге СМБ и государства, вызовы, стоящие перед частным сектором, определены основные препятствия для развития, предложено создание единой и прозрачной платформы сотрудничества властей и частных структур.

Ключевые слова: власть, бизнес, формы взаимодействия, вызовы, препятствия, платформа сотрудничества.

В России усиливается значение бизнеса в развитии экономики. Все субъекты рынка включены в те или иные формы сотрудничества между органами власти и средним и малым бизнесом (СМБ). Эффективность данного взаимодействия является основой роста частного сектора и его институтов в России. Однако в настоящее время сотрудничество бизнеса и власти не характеризуется позитивными оценками [9, с. 182].

Ключевые цели функционирования предприятия - получение максимальной прибыли и расширение представленности на рынке, а у государства основными целями являются получение максимальных налоговых отчислений в бюджет и постоянное увеличение суммы поступлений в бюджет. В то же время на повестке дня у органов власти стоит и вопрос поддержки развития частной сферы и благоприятствования деловой активности.

СМБ служит основой для роста и развития даже крупных деловых структур, играя роль обслуживающего звена. Чтобы государственно-частное партнерство (ГЧП) было эффективно и позволяло достигать целей как общества, так и собственников бизнеса, требуются открытость и честность в сотрудничестве между бизнесом и властью, соблюдение взаимной целесообразности [1]. Актуальность этой потребности обусловлена важностью СМБ в повышении эффективности национальной экономики.

Сейчас существует несколько форм взаимодействия органов власти и частных организаций. Перечислим важнейшие:

1) институт ГЧП с участием СМБ;

2) профсоюзы;

3) совместный контроль социальных и экономических аспектов функционирования частных структур; 
4) электронное правительство (e-govemment).

Также укажем основные нормативные акты, регламентирующие сотрудничество между частными и государственными структурами:

1. Конституция России;

2. Гражданское законодательство;

3. Президентские указы;

4. Федеральный закон от 24.07.2007 № 209-Ф3 «О развитии малого и среднего предпринимательства в Российской Федерации».

Принятие последнего закона было очень важной ступенью развития сотрудничества СМБ и власти. Закон учитывает все параметры частных структур, регламентирует критерии и принципы государственной политики в отношении развития бизнеса, а также порядок сотрудничества частных структур и властей.

Рассмотрим проблемные зоны в сегодняшнем диалоге СМБ и государства.

Так, низкая финансовая обеспеченность местных органов власти приводит к необходимости актуализировать поиск и использовать нематериальные ресурсы для поднятия уровня развития территорий [9].

В то же время если предоставить частному сектору «избыточные мощности» местных сообществ, то это позволит рационализировать практики социального партнерства [10]. Слабо применяется городская инициатива сотрудничества (Sharing City Initiative), которая может помочь нуждающимся в общественной инфраструктуре, таких, как конференц-залы, парковка, публичные библиотеки и т. п. [11].

Некоторые авторы считают, что следует отказаться от рамочных образцов, навязываемых сверху, в качестве форм сотрудничества власти и бизнеса и больше проявлять инициативу на местах, учитывая разнообразие муниципалитетов [8, с. 20].

В промышленно развитых экономиках СМБ играет активную роль в развитии экономики и общества, повышении качества жизни населения. Частный сектор формирует существенную долю ВВП и обеспечивает занятость значительной части лиц. Для успешной деятельности представители СМБ нуждаются в поддержке властей и имеют целый ряд инфраструктурных потребностей, которые они не в состоянии обеспечить самостоятельно.

Главными потребностями в этом ряду являются обеспечение ресурсами на этапе формирования бизнеса и направление к минимальному уровню административных и других неоперационных затрат, таких, как правовая защита и информационное обеспечение, корректное оформление документации, проверка добропорядочности партнеров и нахождение поставщиков.

Во многом эффективному сотрудничеству бизнеса и власти должно способствовать электронное правительство. Исходя из сущности электронного правительства [12] как концепции государственного управления, выделим основные составляющие элементы и функции:

- предоставление публичных услуг онлайн через единую цифровую платформу с высокой степенью безопасности;

- использование единых защищенных систем баз данных правительственных органов для представления публичных услуг и информирования о работе государственных органов;

- применение электронного взаимодействия в трансакциях государственных ор- 
ганов с различными субъектами;

- обеспечение участия общества в государственном управлении (цифровая демократия).

Следовательно, электронное правительство позволяет решить или снизить проблемы бюрократизации, временных затрат на принятие решений, ошибок, коррупции.

В мировой практике введены международные измерения развития различных составляющих информационного общества, в том числе электронного правительства. Организация Объединенных Наций составляет рейтинг развития электронного правительства - E-government development rank (табл. 1).

Как видно из таблицы 1, позиция России в индексе развития электронного правительства снижается при одновременной высокой трансформации государственного управления за счет информационно-коммуникационных технологий. Опрос, проведенный BCG, показал, что Россия на третьем месте как по темпам роста, так и по интенсивности использования цифровых госуслуг, опередив почти втрое среднемировой уровень - $42 \%$ против $15 \%$ [7].

Тем не менее, практическая реализация электронного правительства связана с закреплением за государством новых функций, которые соответствуют информационноцифровой сетевой организации и коммуникации, а также процессов прогнозирования и форсайтинга.

Таблица 1. Динамика рейтинга развития электронного правительства ООН

\begin{tabular}{|l|c|c|c|c|}
\hline \multicolumn{1}{|c|}{ Страна } & $\begin{array}{c}\text { Позиция 2012/ } \\
\text { значение } \\
\text { индекса }\end{array}$ & $\begin{array}{c}\text { Позиция 2014/ } \\
\text { значение } \\
\text { индекса }\end{array}$ & $\begin{array}{c}\text { Позиция 2016/ } \\
\text { значение } \\
\text { индекса }\end{array}$ & $\begin{array}{c}\text { Позиция } \\
\text { 2018/ } \\
\text { значение } \\
\text { индекса }\end{array}$ \\
\hline Дания & $4 / 0,8889$ & $16 / 0,8162$ & $9 / 0,8510$ & $1 / 0,915$ \\
\hline Австралия & $12 / 0,8381$ & $2 / 0,9103$ & $2 / 0,9143$ & $2 / 0,905$ \\
\hline $\begin{array}{l}\text { Республика } \\
\text { Корея }\end{array}$ & $1 / 0,9283$ & $1 / 0,9462$ & $3 / 0,8915$ & $3 / 0,901$ \\
\hline $\begin{array}{l}\text { Великобрита- } \\
\text { ния }\end{array}$ & $3 / 0,8960$ & $8 / 0,8695$ & $1 / 0,9193$ & $4 / 0,8999$ \\
\hline Швеция & $7 / 0,8599$ & $14 / 0,8825$ & $6 / 0,8704$ & $5 / 0,8882$ \\
\hline Финляндия & $9 / 0,8505$ & $10 / 0,8449$ & $5 / 0,8817$ & $6 / 0,8815$ \\
\hline Сингапур & $10 / 0,8474$ & $3 / 0,9076$ & $4 / 0,8828$ & $7 / 0,8812$ \\
\hline$\ldots$ & $\ldots$ & $\ldots$ & & $\ldots$ \\
\hline Россия & $27 / 0,7345$ & $27 / 0,7296$ & $35 / 0,7215$ & $32 / 0,7969$ \\
\hline$\ldots$ & $\ldots$ & $\ldots$ & & $\ldots$ \\
\hline Гвинея-Бисау & $182 / 0,1945$ & $182 / 0,1609$ & $181 / 0,1818$ & $187 / 0,1887$ \\
\hline ЦАР & $180 / 0,2043$ & $192 / 0,0908$ & $190 / 0,0902$ & $189 / 0,1337$ \\
\hline Эритрея & $189 / 0,1092$ & $189 / 0,1076$ & $188 / 0,1256$ & $190 / 0,1257$ \\
\hline Чад & $175 / 0,2239$ & $185 / 0,1418$ & $183 / 0,1791$ & $191 / 0,1214$ \\
\hline $\begin{array}{l}\text { Южный } \\
\text { Судан }\end{array}$ & $188 / 0,1119$ & $191 / 0,0946$ & $192 / 0,0593$ & $192 / 0,1095$ \\
\hline Нигер & $190 / 0,0640$ & $193 / 0,0139$ & $193 / 0,0270$ & $193 / 0,0566$ \\
\hline Сомали & & \multicolumn{2}{|c|}{} \\
\hline
\end{tabular}

Составлено на основе [5]. 
Как нам представляется, надо, используя институциональный подход к трансформации информационного общества и цифровой экономики, акцентировать внимание не на конкретных результатах индексов, а на эффективности организационно-управленческих условий и системной управляемости. Использование институционального подхода в совершенствовании процесса управления взаимосвязанных подсистем (организационно-экономической, инновационной, технологической, технической, промышленной, социальной, финансовой, правовой, экологической) имеет значение для содержательной составляющей. Формирование электронного правительства можно определить как институциональную трансформацию с соответствующими трансформационными и трансакционными издержками.

На наш взгляд, российская власть нуждается в благополучии частных структур ещё сильнее, чем последние зависят от ее поддержки. Власть это осознает, однако не формирует благоприятных условий сотрудничества.

Структуры российской власти выступают инициаторами и формируют запрос к бизнесу для совместного сотрудничества, в то время как в большинстве развитых экономик именно частные структуры более активны в роли инициаторов развития инфраструктуры, государство же отвечает за экономическую целесообразность соответствующих проектов.

Курс развития частных структур в России значительно отличается от того, что реально требуется обществу и для чего существуют ресурсы. Разные регионы России демонстрируют различные практики поддержки СМБ и уровни развития такого бизнеса. Наиболее успешное развитие СМБ при поддержке власти заметно в регионах, руководство которых целенаправленно и последовательно реализует проекты развития предпринимательства. Среди них Санкт-Петербург, Москва, Краснодарский край. И, напротив, есть регионы, в которых развитие СМБ не является центром внимания властей [3].

Взаимосвязь между региональной политикой и реальным состоянием частных структур показывает, что, если власть обратит более пристальное внимание на развитие СМБ и повысит эффективность сотрудничества с ним, частный сектор послужит драйвером роста эффективности региональной экономики и поможет решить проблемы безработицы и дефицита бюджета как на региональном, так и на местном уровне [4, c. 204].

Сегодня частный сектор сталкивается с массой вызовов. Перечислим основные:

1) низкое качество или отсутствие действенной системы информационнотехнологической поддержки СМБ;

2) неразвитая система поддержки предпринимательства;

3) необходимость совершенствования законодательства, регламентирующего частную предпринимательскую деятельность;

4) неэффективное налогообложение малого бизнеса;

5) отсутствие специализированной денежно-кредитной поддержки СМБ;

6) по-прежнему высокие и многочисленные административные барьеры для создания и роста бизнеса.

Основное препятствие в развитии предпринимательства в России - отсутствие прозрачной и работающей системы благоприятствования и сопровождения предпринимательства, включая недостаток информационно-технологического ресурса поддержки.

Другой фактор медленного роста частного предпринимательства - многочисленные административные барьеры, с которыми предприниматели сталкиваются при регистрации своих организаций, получении лицензий и разрешений на свою деятельность, поиске и получении площадей для производства и торговли. Контролирующие органы 
тоже не облегчают деятельность представителей СМБ - количество проверок неоправданно велико и не мотивировано интересами общества.

Для преодоления указанных препятствий считаем целесообразным создание единой и прозрачной платформы сотрудничества властей и частных структур, которая будет служить связующим звеном и помогать в решении существующих проблем предпринимателей.

Целями данной платформы могут быть:

- создание простого и понятного механизма организации малых предприятий на базе цифровой инфраструктурной платформы с пошаговым описанием и сопровождением на основе блокчейн-технологии и использованием всех её преимуществ [2, c. 424];

- цифровое обеспечение ведения бизнеса, включая решение административных задач, осуществление проверок, лицензирование и др.;

- рост частного сектора и развитие предпринимательства.

Дополнительными задачами такой платформы будут:

- рост созидательного (производственного) отечественного предпринимательства товаров и услуг, а не посредничества в перераспределении зарубежных товаров;

- повышение качества жизни и обеспечение широчайшего ассортимента качественной продукции и услуг во всех регионах.

В основу платформы ляжет ГЧП. Региональные и федеральные власти смогут формировать запросы к сообществу частных предпринимателей, в ответ на которые будут создаваться новые малые и средние предприятия.

Таким образом, экономическая система в информационном обществе приобретает новые характеристики и предоставляет государству новые возможности для развития с помощью информационно-цифровых технологий и электронно-сетевых институтов. Ради повышения благоприятности сотрудничества частного сектора и власти рекомендуется создать инновационную платформу на основе блокчейн-технологии, с помощью которой будет осуществляться прозрачная и понятная коммуникация, будет снят барьер недоступного взаимодействия и осуществлена практическая поддержка предпринимательства.

\section{Литература}

1. Алиев О.М. Развитие управления на принципах ГЧП в России // Конкурентоспособность в глобальном мире: экономика, наука, технологии. - 2017. - № 10-7. C. 819-823.

2. Алиев O.M., Омарова 3.А. Возможности блокчейн-технологии для повышения эффективности государственно-частного партнерства // Региональные проблемы преобразования экономики: интеграционные процессы и механизмы формирования и социально-экономическая политика региона. Материалы IX МНПК. - Махачкала: ИСЭИ ДНЦ РАН, 2018. - С. 422-425.

3. Гачегов М.A., Охрименко А.В. Малое и среднее предпринимательство в России в 2017 году: состояние сектора, система государственной поддержки // Российское предпринимательство. - 2018. - Т. 19, № 12. - С. 3887-3902.

4. Завьялов Д.В., Сагинова О.В., Завьялова Н.Б. Проблемы и задачи развития малого и среднего предпринимательства в России // Российское предпринимательство. 2017. - Т. 18, № 3. - С. 203-214.

5. Исследование ООН: рейтинг стран мира по уровню развития электронного правительства. - Режим доступа: https://gtmarket.ru/ratings/e-government-survey/info (дата обращения 10.12.2019). 
6. Плеслов А.А. Факторы и возможности развития малого предпринимательства // Российское предпринимательство. - 2018. - Т. 19, № 2. - С. 507-518.

7. Россия оказалась среди мировых лидеров по использованию цифровых госуслуг. - Режим доступа: https://ria.ru/20190313/1551739374.html (дата обращения 10.12.2019).

8. Чепуренко А.Ю. Совмещая универсальные компетенции с национальной спецификой: поддержка малого и среднего предпринимательства // Вопросы государственного и муниципального управления. - 2017. - № 1. - С. 7-30.

9. Фролова E.В., Медведева Н.В. Сотрудничество бизнеса и местной власти: проблемы и новые возможности // Вопросы государственного и муниципального управления. - 2018. - № 1. - С. 181-196.

10. Bauer R.M., Gegenhuber T. Crowdsourcing: Global search and the twisted roles of consumers and producers // Organization. - 2015. - Vol. 22, Issue 5. - P. 661-681. URL: https://doi. org/10.1177/1350508415585030

11. Moon M.J. Government-driven Sharing Economy: Lessons from the Sharing City Initiative of the Seoul Metropolitan Government // Journal of Developing Societies. - 2017. Vol. 33, № 2. - P. 223-243.

12. World Public Sector Report 2003: e-Government at the Crossroads. Departament of Economic and Social Affairs. United Nations, 2003. URL: http://unpan1.un.org/intradoc/groups/public/documents/un/unplan012733.pdf (дата обращения 10.12.2019).

Поступила в редакиџию 13 января 2020 г.

UDC 338.2

DOI: $10.21779 / 2500-1930-2020-35-1-19-24$

\section{The Analysis of Government and Business Cooperation Problems}

\section{O.M. Aliev}

Dagestan State University Branch in the city of Kizlyar; Russia, 368832, Kizlyar, S.Stalskyst., 1e; oaom651@mail.ru

The importance of business in the development of the Russian economy is gradually increasing. To increase the return on public-private partnerships, openness and honesty in cooperation between business and government, the observance of mutual expediency is required in order to achieve the goals of both society and business owners. The problem areas in today's dialogue between the SMB and the state are examined, the challenges facing the private sector, the main obstacles to development are identified, the creation of a single and transparent platform for cooperation between authorities and private structures is proposed.

Keywords: power, business, forms of interaction, challenges, obstacles, cooperation platform.

Received 13 January, 2020 